\title{
Dietary and lifestyle characteristics associated with normal-weight obesity: the National FINRISK 2007 Study
}

\author{
Satu Männistö ${ }^{1 *}$, Kennet Harald ${ }^{1}$, Jukka Kontto ${ }^{1}$, Marjaana Lahti-Koski ${ }^{2}$, Niina E. Kaartinen ${ }^{1}$, \\ Suoma E. Saarni ${ }^{1}$, Noora Kanerva ${ }^{1,3}$ and Pekka Jousilahti ${ }^{1}$ \\ ${ }^{1}$ Department of Chronic Disease Prevention, National Institute for Health and Welfare, \\ PO Box 30, 00271, Helsinki, Finland \\ ${ }^{2}$ Finnish Heart Association, PO Box 50, 00621 Helsinki, Finland \\ ${ }^{3}$ Department of Public Health, University of Helsinki, PO Box 40, O0014 Helsinki, Finland \\ (Submitted 1 November 2012 - Final revision received 24 June 2013 - Accepted 18 July 2013 - First published online 14 November 2013)
}

\section{Abstract}

The aim of the present study was to compare the lifestyle (leisure-time physical activity, smoking habits and alcohol consumption) and dietary (energy-yielding nutrients, dietary fibre and foods) factors of Finns with a new syndrome called normal-weight obesity (NWO) with those of lean and overweight Finns. The representative population-based study included 4786 participants (25-74 years) from the National FINRISK 2007 Study with a health examination and questionnaires. Food intake was assessed using a validated FFQ. NWO was defined to include those with a normal BMI $\left(<25 \mathrm{~kg} / \mathrm{m}^{2}\right)$ but excessive body fat (for men $\geq 20 \%$ and for women $\left.\geq 30 \%\right)$ according to WHO definitions. The proportion of participants with a normal BMI was $28 \%$ in men and $42 \%$ in women. Of these, $34 \%$ of the men and $45 \%$ of the women had the NWO syndrome (among all the participants, 10 and 19\%, respectively). The waist circumference of the NWO participants was between that of the lean and overweight participants. Some potential risk factors, such as physical inactivity, (ex)-smoking and alcohol consumption, were related to NWO. In general, the intakes of energy-yielding nutrients were not associated with NWO. Instead, some healthy dietary factors (e.g. low intakes of meat and soft drinks) as well as unhealthy factors (e.g. low intakes of root vegetables, cereals and fish and high intake of confectionery) were related to NWO. The findings might explain why the NWO participants were of normal weight, but had an excessive body fat percentage. In conclusion, the proportion of normal-weight participants with an excessive body fat percentage was surprisingly high. The identification of NWO people may be of importance because although they appear lean, they have some unhealthy lifestyle and dietary habits related to obesity and overall health.

\section{Key words: Diet: Lifestyle: Obesity: Physical activity: Surveys}

The proportion of obese adults has reached an epidemic scale all around the world ${ }^{(1)}$, moving steadily away from the Healthy People 2010 goal of $15 \%$ obesity prevalence (BMI $\left.\geq 30 \mathrm{~kg} / \mathrm{m}^{2}\right)^{(2)}$. For example, the prevalence of obesity has reached $20-30 \%$ in European countries, $30 \%$ in the USA and $70 \%$ in Polynesia ${ }^{(1)}$. Nearly $70 \%$ of the Finnish working-age men and half of the women are classified as at least overweight $\left(\right.$ BMI $\geq 25 \mathrm{~kg} / \mathrm{m}^{2}$ ) and over $20 \%$ of them as obese ${ }^{(3)}$. The WHO has estimated that there will be about 1.5 billion overweight and obese people worldwide by 2015 if the current trends continue $^{(4)}$.

BMI has been the most commonly used anthropometric measure to diagnose obesity and predict the risk of chronic diseases. Waist circumference has also been used to assess abdominal obesity. However, it has been reported that there are some obese subjects with normal metabolic indicators, such as blood lipid and glucose concentrations (metabolically healthy obese), as well as subjects who are metabolically obese but of normal weight ${ }^{(5,6)}$. Furthermore, a new syndrome called normal-weight obesity (NWO) has recently been identified among normal-weight subjects (BMI $<25 \mathrm{~kg} / \mathrm{m}^{2}$ ) whose amounts of fat stores (body fat percentage) are above the recommendations, e.g. by WHO definitions ( $\geq 20 \%$ for men and $\geq 30 \%$ for women) ${ }^{(7)}$.

Differences in the levels of pro-inflammatory markers have been found among NWO women compared with those among lean women (without excessive fat storages) in an Italian study including less than 100 subjects $^{(7,8)}$. In a random sample of inhabitants in the Swiss city of Lausanne ( $n$ 6125), the prevalence of the NWO syndrome has been reported to

Abbreviations: EI, energy intake; NWO, normal-weight obesity.

*Corresponding author: Dr S. Männistö, fax +358 29524 8338; email satu.mannisto@thl.fi 
be much higher in women than in men, regardless of the four different cut-off points used for excessive body fat $30 \%$ for both men and women; fixed sex-specific values, $29 \cdot 1 \%$ for men and $37 \cdot 2 \%$ for women, as proposed in the National Health and Nutrition Examination Survey (NHANES); age- and sex-specific values derived from an international study, e.g. $26 \%$ for white men aged $20-39$ years; or age- and sex-specific 95th percentiles for the Swiss population) ${ }^{(9)}$. It has been reported that the levels of cardiovascular risk factors are higher in NWO women than in lean women ${ }^{(10)}$. The two previous studies related to risk factors were restricted to only women. Furthermore, there were no previous examinations of dietary factors in relation to the NWO syndrome.

In the present study, we assessed the prevalence of the NWO syndrome and its associations with lifestyle factors (leisure-time physical activity, smoking habits and alcohol intake) as well as energy, energy-yielding nutrients, dietary fibre and whole diet. In all, we included twenty-nine food groups such as cereals (rye and wheat), potatoes, vegetables, fruits, fruit juice, meat (pork, beef, poultry and processed meat) and milk (liquid milk, fermented milk and cheese), which are the main components of the Finnish diet or related to obesity based on the previous literature. The main aims were to identify factors that were specifically related to NWO (protective or risk factors for obesity): by first comparing three weight categories (lean, NWO and overweight participants) and then identifying factors that were similar between lean and NWO participants (and might be potential protective factors for obesity) or identifying factors that were similar between NWO and overweight participants (and might be potential risk factors for obesity/high body fat percentage). The study participants were a representative sample of the Finnish population.

\section{Methods and procedures}

\section{Sampling}

The participants took part in two phases of the National FINRISK 2007 Study conducted by the National Institute for Health and Welfare in Finland ${ }^{(3)}$. An independent random sample of 10000 men and women aged 25-74 years was drawn from the national population register in five large geographical areas at the end of 2006. The sample was stratified by sex, 10-year age category and area. The first phase took place between January and March 2007 including a health examination (including measurements of weight, height, waist circumference, hip circumference and blood pressure as well as collection of blood samples) and health questionnaires on sociodemographic factors, health behaviour (e.g. leisure-time physical activity, smoking habits and alcohol intake) and medical history. All 6258 participants who took part in the first phase of the survey were invited to a more detailed examination on the dietary, lifestyle and genetic determinants of obesity and the metabolic syndrome from April to June 2007. This phase included measurements of anthropometric parameters (weight, waist circumference, hip circumference and body fat percentage), oral glucose tolerance test and a self-administered FFQ. The response rate for the second phase was $80 \%$; thus, 5024 participated in the study. Of these, $5 \%$ ( $n$ 238) were considered non-eligible because of missing dietary information and anthropometric data, heart pacemaker use and pregnancy. Consequently, the final sample included 2216 men and 2570 women (48\% of those invited to participate).

The study was conducted according to the guidelines laid down in the Declaration of Helsinki, and all procedures involving human subjects were approved by the Ethics Committee of Helsinki and Uusimaa Hospital District. Written informed consent was obtained from all the participants for both field research phases.

\section{Anthropometric measures}

At the study sites, specially trained nurses measured weight, height, waist circumference and hip circumference of the participants using standardised international protocols ${ }^{(11)}$. All anthropometric measures were assessed with the participants wearing light clothing and being bare feet. The measurement of weight was rounded to the nearest $0 \cdot 1 \mathrm{~kg}$ and that of height to the nearest $0 \cdot 1 \mathrm{~cm}$. BMI was calculated as the weight in $\mathrm{kg}$ divided by the squared height in $\mathrm{m}\left(\mathrm{kg} / \mathrm{m}^{2}\right)$. Waist circumference was measured midway between the lower rib margin and iliac crest. The measurement of waist was rounded to the nearest $0.5 \mathrm{~cm}$. Furthermore, a bioelectrical impedance instrument (TANITA TBF-300MA, Tanita Corporation of America, Inc.) was used to assess body composition, such as body fat percentage. The TANITA method is comparable to a four-compartment method ${ }^{(12)}$.

Participants with a BMI $<25 \mathrm{~kg} / \mathrm{m}^{2}$ and a body fat percentage under the sex-specific cut-off point defined by the WHO, $<20 \%$ for men and $<30 \%$ for women ${ }^{(13)}$, were classified as lean. Normal-weight participants (BMI $<25 \mathrm{~kg} / \mathrm{m}^{2}$ ) whose body fat percentage exceeded the cut-off points ( $\geq 20 \%$ for men and $\geq 30 \%$ for women) were classified as having the NWO syndrome. Participants with a BMI $\geq 25 \mathrm{~kg} / \mathrm{m}^{2}$ were considered overweight, including both overweight $\left(25 \mathrm{~kg} / \mathrm{m}^{2} \leq\right.$ BMI $<30 \mathrm{~kg} / \mathrm{m}^{2}$ ) and obese $\left(\mathrm{BMI} \geq 30 \mathrm{~kg} / \mathrm{m}^{2}\right.$ ) participants. Thus, there were three weight categories: lean; NWO syndrome; overweight. The analyses were carried out with and without six underweight men and twenty-three women (BMI $<18.5 \mathrm{~kg} / \mathrm{m}^{2}$ ) and with and without those overweight participants $(6 \%$ of the men and $2 \%$ of the women) who had a normal body fat percentage.

\section{Lifestyle characteristics}

A self-administered health questionnaire was sent to the participants with an invitation letter for the first health examination. Education, measured as the total number of school years, was divided into birth cohort-specific tertiles. Self-reported leisure-time physical activity consisted of activity outside work and was assessed according to four categories: low (mainly reading, watching television or other light activities); moderate (walking, cycling, gardening or other moderate activities at least $4 \mathrm{~h} /$ week); active (brisk running, 
walking, cross-country skiing, swimming or other physically demanding activities at least $3 \mathrm{~h} /$ week); highly active (competitive sports and physically demanding activities several times per week). Because of the low number of highly active participants, the two highest categories were merged into one category related to high leisure-time physical activity. The participants were categorised as never smokers, exsmokers or current smokers. Based on alcohol intake over the previous 12 months, the participants were categorised as abstainers or alcohol users.

\section{FFQ}

Food intake over the previous 12 months was assessed using a validated self-administered FFQ updated for the present study $^{(14,15)}$. The average use of 131 food items and mixed dishes was recorded by nine frequency categories ranging from never or seldom to at least six times a day. The portion size was fixed for each food item or mixed dish (e.g. slice and glass) based on the dietary interviews of the national FINDIET 2007 Study. The reporting of additional items consumed frequently but not listed in the FFQ was also allowed. The participants completed the FFQ during the $2 \mathrm{~h}$ oral glucose tolerance test at the study site, where a trained study nurse reviewed the questionnaire. If the participants were not able to complete all the three questionnaires (healthy questionnaire, FFQ and mental questionnaire) at the study site, they could take the incomplete questionnaires to their homes, fill them in later and send to the National Institute for Health and Welfare. The final decision for the completeness of FFQ was made by a nutritionist. Exclusions were made due to incompletely filled FFQ (e.g. total or partly empty questionnaires or the idea of the FFQ being not understood, $n$ 74) and daily energy intake (EI) cut-off points corresponding to $0.5 \%$ at both ends of the daily EI distributions for men and women ( $n$ 48). The average daily intakes of energy, energyyielding nutrients, dietary fibre and twenty-nine food groups (e.g. 'Fruits' includes fruits and berries as such or from desserts and sweet pastries) were calculated with the national food composition database, Fineli ${ }^{\circledR}$ (National Institute for Health and Welfare), using in-house software ${ }^{(16)}$.

\section{Statistical analyses}

The means and 95\% CI of anthropometric measures and lifestyle and dietary factors were calculated based on the weight categories separately for men and women. The distributions of dietary variables were tested for normality using the ShapiroWilk test, and because the null hypothesis was not rejected, log transformation was not needed. Sample weights by age, sex and region (2007) were used in all the analyses. Furthermore, the intake of dietary fibre was adjusted for energy according to the residual method ${ }^{(17)}$. For all variables, we used simple age-adjusted models (and energy-adjusted ones for fibre and foods). The multivariable models were adjusted for age, education, leisure-time physical activity, smoking and alcohol intake (and energy for fibre and foods). The aim was to find factors that were specifically related to
NWO (protective or risk factors for obesity) when comparing the three weight categories. Differences across the weight categories were assessed using linear regression ( $F$ test, means) or logistic regression (Wald test, \%). We also tried to determine whether there were differences between lean and NWO participants or between NWO and overweight participants. Differences between the specific weight categories were determined using the $t$ test (means) or Wald test (\%). All $P$ values were two sided, and $P<0.05$ was considered to be statistically significant.

The analyses were also carried out with and without under-reporters. To take into account the possible misreporting of EI, the ratio of the reported EI to the predicted BMR (EI/BMR) was calculated using WHO guidelines ${ }^{(18)}$, and the participants were classified as either under-reporters $(\mathrm{EI} / \mathrm{BMR} \leq 1.14)$ or plausible reporters (EI/BMR $>1.14)$ based on the cut-off points proposed by Goldberg et al. ${ }^{(19)}$ and revised by Black $^{(20)}$.

The analyses were carried out using the SAS statistical software package version 8.2 (SAS Institute, Inc.).

\section{Results}

The mean age was 53 (SD 13) years for men and 52 (SD 14) years for women. The mean BMI was $27 \cdot 4$ (SD $4 \cdot 2) \mathrm{kg} / \mathrm{m}^{2}$ for men and $27 \cdot 0$ (SD 5.4$) \mathrm{kg} / \mathrm{m}^{2}$ for women. In all, $28 \%$ of the men and $42 \%$ of the women had normal weight. Of these having normal weight, $34 \%$ of the men and $45 \%$ of the women had the NWO syndrome (among all the participants, 10 and $19 \%$, respectively).

NWO men were the oldest, most leisure-time physically inactive and most likely to be current smokers compared with the other weight categories (Table 1). The prevalence of being ex-smokers, alcohol intake and anthropometric measures in NWO men fell between those in lean and overweight men. NWO women had the highest prevalence of being ex-smokers and consumed high amounts of alcohol compared with the other weight categories (Table 2). Furthermore, in NWO women, mean age, the prevalence of being low leisure-time physically inactive and anthropometric measures were between those in the lean and overweight categories. NWO and overweight women were more likely to be current smokers compared with lean women. When underweight participants with a BMI $<18.5 \mathrm{~kg} / \mathrm{m}^{2}$ ( $n$ 29) were excluded, the results obtained for lifestyle factors and anthropometric measures based on the weight categories remained similar (data not shown). Furthermore, a normal body fat percentage emerged in $6 \%$ of the overweight men and $1 \%$ of the overweight women. When these participants were excluded, the results remained similar (data not shown).

No statistically significant differences were found for the intakes of energy-yielding nutrients and fibre between lean and NWO men or NWO and overweight men (Table 3). The protein (percentage of energy) intake of NWO women was similar to that of lean women, but lower than that of overweight women (Table 4). However, the intakes of alcohol (percentage of energy) and fibre were similar between NWO and overweight women, but their intakes of alcohol 
Table 1. Lifestyle factors and anthropometric measures by weight categories in men (Mean values, $95 \%$ confidence intervals and percentages)

\begin{tabular}{|c|c|c|c|c|c|c|c|c|}
\hline & \multicolumn{2}{|c|}{ Lean $(n 416) \ddagger$} & \multicolumn{2}{|c|}{$\begin{array}{l}\text { Normal-weight obese } \\
\quad(n 215) \ddagger\end{array}$} & \multicolumn{2}{|c|}{ Overweight $(n$ 1585) } & \multirow[b]{2}{*}{$P \neq \S$} & \multirow[b]{2}{*}{$P \S \|$} \\
\hline & Mean & $95 \% \mathrm{Cl}$ & Mean & $95 \% \mathrm{Cl}$ & Mean & $95 \% \mathrm{Cl}$ & & \\
\hline Age (years) & $40 \cdot 1$ & $39 \cdot 1,41 \cdot 1$ & $54 \cdot 4^{*} \dagger$ & $52 \cdot 5,56 \cdot 2$ & 48.9 & $48 \cdot 2,49 \cdot 5$ & $<0.0001$ & $<0.0001$ \\
\hline Education (years) & $13 \cdot 5$ & $13 \cdot 2,13 \cdot 8$ & $12 \cdot 6^{\star}$ & $12 \cdot 0,13 \cdot 1$ & $12 \cdot 5$ & $12 \cdot 4,12 \cdot 7$ & $<0.0001$ & 0.16 \\
\hline Low leisure-time physical activity (\%) & \multicolumn{2}{|r|}{$63 \cdot 3$} & \multicolumn{2}{|c|}{$77 \cdot 1^{*} \dagger$} & \multicolumn{2}{|r|}{$71 \cdot 6$} & $<0.0001$ & $<0.0001$ \\
\hline Current smoker (\%) & \multicolumn{2}{|r|}{18.6} & \multicolumn{2}{|c|}{$26 \cdot 0^{*} \dagger$} & \multicolumn{2}{|r|}{$21 \cdot 0$} & $<0.0001$ & $<0.0001$ \\
\hline Ex-smoker (\%) & & $25 \cdot 1$ & & & \multirow{2}{*}{\multicolumn{2}{|c|}{$\begin{array}{l}35.9 \\
79.9\end{array}$}} & $<0.0001$ & $<0.0001$ \\
\hline Alcohol consumption, last 12 months (\%) & \multicolumn{2}{|r|}{$69 \cdot 3$} & \multicolumn{2}{|c|}{$77 \cdot 7^{\star}+$} & & & $<0.0001$ & $<0.0001$ \\
\hline BMI $\left(\mathrm{kg} / \mathrm{m}^{2}\right)$ & $23 \cdot 0$ & $22 \cdot 8,23 \cdot 3$ & $24 \cdot 1^{*} \dagger$ & $23 \cdot 7,24 \cdot 6$ & 28.9 & $28 \cdot 8,29 \cdot 1$ & $<0.0001$ & $<0.0001$ \\
\hline Body fat $(\%)$ & $17 \cdot 4$ & $17 \cdot 0,17 \cdot 9$ & $22 \cdot 1^{*} \dagger$ & $21 \cdot 4,22 \cdot 8$ & $26 \cdot 8$ & $26 \cdot 6,27 \cdot 1$ & $<0.0001$ & $<0.0001$ \\
\hline Waist circumference $(\mathrm{cm})$ & $86 \cdot 7$ & $85 \cdot 9,87 \cdot 4$ & $91 \cdot 1^{*} \dagger$ & $89.9,92 \cdot 4$ & $102 \cdot 1$ & $101 \cdot 6,102 \cdot 5$ & $<0.0001$ & $<0.0001$ \\
\hline Abdominal obesity (\%) & \multicolumn{2}{|r|}{0} & \multicolumn{2}{|r|}{$0+\quad-1$} & & $43 \cdot 3$ & $<0.0001$ & $<0.0001$ \\
\hline
\end{tabular}

* Mean values were significantly different from those of lean men $(P<0.05 ; t$ test $)$

$\dagger$ Mean values were significantly different from those of overweight men $(P<0.05 ; t$ test).

$\ddagger$ Adjusted for age.

$\S$ Differences across the weight categories were assessed using the $F$ test (means) or Wald test (\%).

$\|$ Adjusted for age, education, leisure-time physical activity, smoking, alcohol consumption and energy intake.

I Women: $>88 \mathrm{~cm}$; men: $>102 \mathrm{~cm}$

(percentage of energy) were higher and intakes of fibre were lower than those of lean women.

The intake of beef was highest in NWO men than in the other weight categories (Table 3). The intakes of poultry, processed meat, coffee, soft drinks and sugar were similar between lean and NWO men, but their intakes of sugar were higher and intakes of other nutrients were lower than those of overweight men. Instead, the intakes of cereals and milk were similar between NWO and overweight men, but their intakes of cereals were lower and intakes of milk were higher than those of lean men. The difference in daily intakes of processed meat was $14 \mathrm{~g}$, soft drinks $52 \mathrm{~g}$ and milk $51 \mathrm{~g}$ between the weight categories

NWO women consumed high amounts of sugar (especially confectionery) and low amounts of root vegetables compared with the other weight categories (Table 4). The intakes of potatoes, vegetables, oil, meat (especially beef, poultry and processed meat), milk and soft drinks were similar between lean and NWO women, but their intakes of oil were higher and intakes of other nutrients were lower than those of overweight women. Instead, the intakes of cereals (especially rye), fish, cheese and tea were similar between NWO and overweight women, but lower than those of lean women. The difference in daily intakes of vegetables was $33 \mathrm{~g}$, soft drinks $38 \mathrm{~g}$ and confectionery $11 \mathrm{~g}$ between the weight categories.

The proportion of under-reporters was $18 \%$ in lean men, $18 \%$ in NWO men and $25 \%$ in overweight men. In women, the percentages were 11,15 and 25 , respectively. In general, when under-reporters were excluded, the results remained similar (data not shown). However, the EI was statistically significantly higher in the overweight participants than in the lean and NWO participants in both the sexes. The intakes of

Table 2. Lifestyle factors and anthropometric measures by weight categories in women (Mean values, 95\% confidence intervals and percentages)

\begin{tabular}{|c|c|c|c|c|c|c|c|c|}
\hline & \multicolumn{2}{|c|}{ Lean $(n$ 594)‡ } & \multicolumn{2}{|c|}{$\begin{array}{l}\text { Normal-weight obese } \\
\qquad(n \text { 482) } \ddagger\end{array}$} & \multicolumn{2}{|c|}{$\begin{array}{l}\text { Overweight } \\
(n \text { 1494)‡ }\end{array}$} & \multirow[b]{2}{*}{$P \neq \S$} & \multirow[b]{2}{*}{$P \S \|$} \\
\hline & Mean & $95 \% \mathrm{Cl}$ & Mean & $95 \% \mathrm{Cl}$ & Mean & $95 \% \mathrm{Cl}$ & & \\
\hline Age (years) & 40.5 & $39.6,41.4$ & $49 \cdot 1^{*} \dagger$ & $48 \cdot 0,50 \cdot 2$ & $51 \cdot 8$ & $51 \cdot 1,52 \cdot 5$ & $<0.0001$ & $<0.0001$ \\
\hline Education (years) & $13 \cdot 7$ & $13.4,13.9$ & 13.4 & $13 \cdot 1,13 \cdot 7$ & $13 \cdot 1$ & $12 \cdot 9,13 \cdot 3$ & 0.0032 & 0.0095 \\
\hline Low leisure-time physical activity (\%) & \multicolumn{2}{|r|}{63.2} & \multicolumn{2}{|c|}{$72 \cdot 4^{*} \dagger$} & \multicolumn{2}{|r|}{$80 \cdot 0$} & $<0.0001$ & $<0.0001$ \\
\hline Current smoker (\%) & \multicolumn{2}{|r|}{$12 \cdot 7$} & \multicolumn{2}{|c|}{$15 \cdot 9^{\star}$} & \multicolumn{2}{|r|}{$15 \cdot 9$} & $<0.0001$ & $<0.0001$ \\
\hline Ex-smoker (\%) & \multicolumn{2}{|r|}{$15 \cdot 8$} & \multirow{2}{*}{\multicolumn{2}{|c|}{$21 \cdot 2^{*} \dagger$}} & \multicolumn{2}{|r|}{$20 \cdot 2$} & $<0.0001$ & $<0.0001$ \\
\hline Alcohol consumption, last 12 months (\%) & \multicolumn{2}{|r|}{$64 \cdot 8$} & & & \multicolumn{2}{|r|}{$59 \cdot 4$} & $<0.0001$ & $<0.0001$ \\
\hline $\mathrm{BMI}\left(\mathrm{kg} / \mathrm{m}^{2}\right)$ & 21.8 & $21 \cdot 5,22 \cdot 1$ & $23 \cdot 6{ }^{*} \dagger$ & $23 \cdot 3,23 \cdot 9$ & $30 \cdot 2$ & $30 \cdot 0,30 \cdot 4$ & $<0.0001$ & $<0.0001$ \\
\hline Body fat $(\%)$ & $25 \cdot 6$ & $25 \cdot 3,26 \cdot 0$ & $33 \cdot 2 *+$ & $32 \cdot 8,33.5$ & $40 \cdot 0$ & $39 \cdot 8,40 \cdot 2$ & $<0.0001$ & $<0.0001$ \\
\hline Waist circumference $(\mathrm{cm})$ & 74.6 & $73.9,75.4$ & $81 \cdot 2^{*} \dagger$ & $80 \cdot 4,82 \cdot 0$ & $96 \cdot 1$ & $95 \cdot 6,96 \cdot 6$ & $<0.0001$ & $<0.0001$ \\
\hline Abdominal obesity (\%)ף & \multicolumn{2}{|r|}{0.6} & \multicolumn{2}{|c|}{$6 \cdot 2^{*} \dagger$} & \multicolumn{2}{|r|}{$72 \cdot 0$} & $<0.0001$ & $<0.0001$ \\
\hline
\end{tabular}

${ }^{*}$ Mean values were significantly different from those of lean women $(P<0.05 ; t$ test $)$.

$\dagger$ Mean values were significantly different from those of overweight women $(P<0.05 ; t$ test).

$\ddagger$ Adjusted for age.

$\S$ Differences across the weight categories were assessed using the $F$ test (means) or Wald test (\%).

$\|$ Adjusted for age, education, leisure-time physical activity, smoking, alcohol consumption and energy intake.

I Women: $>88 \mathrm{~cm}$, men: $>102 \mathrm{~cm}$. 
Table 3. Dietary factors by weight categories in men

(Mean values and $95 \%$ confidence intervals)

\begin{tabular}{|c|c|c|c|c|c|c|c|c|}
\hline & \multicolumn{2}{|c|}{ Lean $(n$ 416) $\ddagger$} & \multicolumn{2}{|c|}{$\begin{array}{l}\text { Normal-weight obese } \\
\qquad(\text { (n 215) } \ddagger\end{array}$} & \multicolumn{2}{|c|}{ Overweight $(n$ 1585) $\ddagger$} & \multirow[b]{2}{*}{$P \neq \S$} & \multirow[b]{2}{*}{$P \S \|$} \\
\hline & Mean & $95 \% \mathrm{Cl}$ & Mean & $95 \% \mathrm{Cl}$ & Mean & $95 \% \mathrm{Cl}$ & & \\
\hline Energy (kJ) & 10986 & 10636,11335 & 11166 & 10601,11732 & 11503 & 11300,11705 & 0.02 & 0.02 \\
\hline Fat $(\mathrm{E} \%)$ & 31.4 & $31.0,31.9$ & $31 \cdot 7$ & $31 \cdot 0,32 \cdot 5$ & 31.6 & $31.4,31.9$ & 0.65 & 0.95 \\
\hline SFA and trans-fatty acid (E\%) & $12 \cdot 0$ & $11 \cdot 7,12 \cdot 2$ & $12 \cdot 4$ & $12 \cdot 0,12 \cdot 7$ & $12 \cdot 1$ & $11 \cdot 9,12 \cdot 2$ & 0.18 & 0.29 \\
\hline Carbohydrates (E\%) & $48 \cdot 3$ & $47 \cdot 8,48 \cdot 8$ & $47 \cdot 4$ & $46 \cdot 6,48 \cdot 3$ & $47 \cdot 1$ & $46 \cdot 8,47 \cdot 4$ & 0.0003 & 0.05 \\
\hline Protein $(\mathrm{E} \%)$ & $17 \cdot 3$ & $17 \cdot 1,17 \cdot 5$ & $17 \cdot 7$ & $17 \cdot 4,18 \cdot 1$ & $17 \cdot 8$ & $17 \cdot 7,18 \cdot 0$ & 0.0001 & $<0.0001$ \\
\hline Alcohol (E\%) & 2.97 & $2 \cdot 61,3.32$ & $3 \cdot 10$ & $2.53,3.67$ & 3.38 & $3.18,3.59$ & 0.09 & 0.68 \\
\hline Fibre $(\mathrm{g})$ q & $27 \cdot 8$ & $27 \cdot 1,28 \cdot 5$ & $26 \cdot 8$ & $25 \cdot 7,27 \cdot 9$ & $27 \cdot 1$ & $26 \cdot 7,27 \cdot 5$ & 0.14 & 0.77 \\
\hline Cereals $(\mathrm{g})$ & 212 & 207,217 & $202^{*}$ & 194,210 & 200 & 198, 203 & 0.0002 & 0.0034 \\
\hline Rye (g) & 64.3 & $60 \cdot 8,67 \cdot 7$ & 63.7 & $58 \cdot 2,69 \cdot 3$ & 65.8 & $63 \cdot 9,67 \cdot 8$ & 0.60 & 0.81 \\
\hline Wheat (g) & 89.7 & $86 \cdot 5,92 \cdot 9$ & 85.6 & $80 \cdot 5,90 \cdot 8$ & $85 \cdot 2$ & $83 \cdot 4,87 \cdot 1$ & 0.04 & 0.11 \\
\hline Potatoes $(\mathrm{g})^{\star \star}$ & 172 & 163,181 & 186 & 171,200 & 182 & 177,187 & 0.09 & 0.20 \\
\hline Vegetables (g) & 263 & 249,277 & 281 & 258,303 & 274 & 266,282 & 0.28 & 0.05 \\
\hline Root vegetables (g) & 49.1 & $45 \cdot 9,52 \cdot 3$ & $49 \cdot 6$ & $44 \cdot 4,54 \cdot 8$ & 47.9 & $46 \cdot 1,49 \cdot 8$ & 0.72 & 0.84 \\
\hline Fruits $(g) \dagger \dagger$ & 259 & 241,277 & 230 & 201,258 & 237 & 227,247 & 0.06 & 0.62 \\
\hline Juices (g) & 148 & 132,163 & 136 & 111,161 & 152 & 143,161 & 0.47 & 0.43 \\
\hline Fat $(\mathrm{g})$ & $50 \cdot 3$ & $48 \cdot 8,51 \cdot 8$ & $50 \cdot 2$ & $47 \cdot 8,52 \cdot 6$ & $50 \cdot 8$ & $49 \cdot 9,51 \cdot 7$ & 0.78 & 0.80 \\
\hline Butter (g) & $8 \cdot 60$ & $7.88,9.33$ & $9 \cdot 12$ & $7 \cdot 95,10 \cdot 29$ & 8.92 & $8.50,9.34$ & 0.67 & 0.81 \\
\hline Margarine (g) & $13 \cdot 6$ & $12 \cdot 5,14 \cdot 7$ & $13 \cdot 6$ & $11 \cdot 9,15 \cdot 4$ & 14.6 & $14 \cdot 0,15 \cdot 3$ & 0.19 & 0.34 \\
\hline Oil (g) & $12 \cdot 5$ & $12 \cdot 0,13 \cdot 0$ & $12 \cdot 2$ & $11 \cdot 4,13.1$ & 11.9 & $11 \cdot 6,12 \cdot 2$ & 0.14 & $0 \cdot 16$ \\
\hline Meat products (g) & 210 & 202,218 & 224 & 211,236 & 231 & 227,236 & $<0.0001$ & 0.0002 \\
\hline Pork (g) & $55 \cdot 8$ & $53 \cdot 1,58 \cdot 5$ & 59.6 & $55 \cdot 2,64 \cdot 0$ & $56 \cdot 3$ & $54.7,57.9$ & 0.34 & 0.39 \\
\hline Beef $(g)$ & $46 \cdot 9$ & $44 \cdot 1,49 \cdot 7$ & $55 \cdot 9^{*} \dagger$ & $51 \cdot 5,60 \cdot 4$ & $49 \cdot 0$ & $47.4,50 \cdot 6$ & 0.0038 & 0.0043 \\
\hline Poultry $(\mathrm{g})$ & $36 \cdot 6$ & $32 \cdot 9,40 \cdot 3$ & $31.7 \dagger$ & $25 \cdot 7,37 \cdot 6$ & $38 \cdot 3$ & $36 \cdot 1,40 \cdot 4$ & 0.11 & 0.05 \\
\hline Sausage, processed meat $(\mathrm{g})$ & $57 \cdot 7$ & $53 \cdot 0,62 \cdot 3$ & $57.0 \dagger$ & $49.5,64.4$ & 71.5 & $68.8,74.1$ & $<0.0001$ & $<0.0001$ \\
\hline Fish $(\mathrm{g})$ & $66 \cdot 0$ & $61 \cdot 6,70 \cdot 5$ & $66 \cdot 3$ & $59 \cdot 1,73 \cdot 4$ & $66 \cdot 3$ & $63 \cdot 8,68 \cdot 9$ & 0.99 & 0.89 \\
\hline Eggs (g) & $29 \cdot 6$ & $27 \cdot 8,31 \cdot 4$ & $31 \cdot 8$ & $28.9,34.8$ & 31.7 & $30 \cdot 7,32 \cdot 8$ & 0.11 & 0.28 \\
\hline Milk products (g) & 631 & 597,666 & 674 & 617,730 & 669 & 649,689 & 0.14 & 0.06 \\
\hline Milk (g) & 369 & 338,400 & 424 & 373,474 & 420 & 402,438 & 0.01 & 0.02 \\
\hline Fermented milk products $(\mathrm{g})$ & 187 & 169,204 & 171 & 143,199 & 176 & 166,186 & 0.49 & 0.93 \\
\hline Cheese $(\mathrm{g})$ & 41.5 & $38 \cdot 3,44 \cdot 6$ & $42 \cdot 7$ & $37 \cdot 7,47 \cdot 8$ & $41 \cdot 3$ & $39 \cdot 5,43 \cdot 1$ & 0.87 & 0.79 \\
\hline Coffee $(\mathrm{g})$ & 388 & 363,413 & $399 \dagger$ & 359,438 & 446 & 431,460 & $<0.0001$ & 0.003 \\
\hline Tea $(\mathrm{g})$ & 137 & 117,157 & 161 & 129,193 & 128 & 116,139 & 0.14 & 0.18 \\
\hline Soft drinks (g) & 81.0 & $64 \cdot 3,97 \cdot 8$ & $70.2 \dagger$ & $43 \cdot 2,97 \cdot 2$ & 122.5 & $112 \cdot 8,132 \cdot 1$ & $<0.0001$ & $<0.0001$ \\
\hline Total sugar (g) & $56 \cdot 6$ & $53 \cdot 5,59 \cdot 7$ & $54 \cdot 3$ & $49 \cdot 3,59 \cdot 3$ & 53.5 & $51 \cdot 7,55 \cdot 3$ & 0.19 & 0.24 \\
\hline Sugar, syrups (g) & 22.4 & $21 \cdot 2,23 \cdot 6$ & $22.5 \dagger$ & $20 \cdot 6,24.4$ & $19 \cdot 9$ & $19 \cdot 2,20 \cdot 6$ & $<0.0001$ & 0.0004 \\
\hline Confectionery (g) & 21.7 & $19 \cdot 1,24.3$ & 19.5 & $15 \cdot 3,23 \cdot 7$ & $18 \cdot 7$ & $17 \cdot 2,20 \cdot 2$ & 0.12 & 0.28 \\
\hline
\end{tabular}

$E \%$, percentage of energy.

${ }^{*}$ Mean values were significantly different from those of lean men $(P<0.05 ; t$ test $)$.

$\dagger$ Mean values were significantly different from those of overweight men $(P<0.05 ; t$ test $)$

$\ddagger$ Intakes of energy-yielding nutrients were adjusted for age; those of fibre and foods were adjusted for age and energy intake.

$\S$ Differences across the weight categories were assessed using the $F$ test.

\| Adjusted for age, education, leisure-time physical activity, smoking, alcohol consumption and energy intake (excluded energy for energy-yielding nutrients).

I Energy adjusted using the residual method.

** 'Potatoes' also includes hot chips and fried potatoes.

††'Fruits' does not include juice.

SFA (men) and protein (men and women) were the lowest in lean women. Furthermore, no differences were found for the intakes of cereals (men), coffee (men), beef (women) and milk (women) between the weight categories.

\section{Discussion}

In the representative Finnish sample of the present study, $28 \%$ of the men and $42 \%$ of the women were of normal weight. Of these, about $40 \%$ had an elevated body fat percentage based on WHO definitions ${ }^{(13)}$. In the entire study population, the prevalence of the NWO syndrome in women (19\%) was twice as high as that in men $(10 \%)$. In the Swiss city of Lausanne, the prevalence of the NWO syndrome was under $1 \%$ for men and between 1 and $28 \%$ for women, depending on the four definitions used (30\% for both men and women; fixed sexspecific values, $29 \cdot 1 \%$ for men and $37 \cdot 2 \%$ for women, as proposed in NHANES; age- and sex-specific values derived from an international study, e.g. 26\% for white men aged 20-39 years; or age- and sex-specific 95th percentiles for the Swiss population $)^{(9)}$. These definitions were not exactly the same as WHO definitions used in the present study (20\% for men and $30 \%$ for women), and thus, the results between the studies are not directly comparable. When we used the definitions of the Swiss study, the prevalence of the NWO syndrome was either non-existent or surprisingly high (data not shown). This phenomenon also occurred in Lausanne. Clearly, more studies and a consensus on the definition of NWO are required.

The proportion of low physically active participants was highest in NWO men compared with the other weight categories, 
Table 4. Dietary factors by weight categories in women

(Mean values and $95 \%$ confidence intervals)

\begin{tabular}{|c|c|c|c|c|c|c|c|c|}
\hline & \multicolumn{2}{|c|}{ Lean ( $n$ 594)‡ } & \multicolumn{2}{|c|}{$\begin{array}{l}\text { Normal-weight obese } \\
\qquad(n \text { 482) } \ddagger\end{array}$} & \multicolumn{2}{|c|}{ Overweight ( $n$ 1494)‡ } & \multirow[b]{2}{*}{$P \ddagger \S$} & \multirow[b]{2}{*}{$P \S \|$} \\
\hline & Mean & $95 \% \mathrm{Cl}$ & Mean & $95 \% \mathrm{Cl}$ & Mean & $95 \% \mathrm{Cl}$ & & \\
\hline Energy (kJ) & 9531 & 9284,9778 & 9304 & 9029, 9578 & 9351 & 9185,9516 & 0.39 & 0.56 \\
\hline Fat $(\mathrm{E} \%)$ & 30.4 & $30 \cdot 0,30 \cdot 8$ & 31.0 & $30.5,31.4$ & 30.5 & $30 \cdot 2,30 \cdot 7$ & 0.11 & 0.08 \\
\hline SFA and trans-fatty acid (E\%) & 11.6 & $11 \cdot 4,11 \cdot 8$ & $11 \cdot 8$ & $11 \cdot 6,12 \cdot 0$ & $11 \cdot 6$ & $11.4,11.7$ & 0.11 & 0.02 \\
\hline Carbohydrates (E\%) & 50.5 & $50 \cdot 1,51 \cdot 0$ & $50 \cdot 1$ & $49 \cdot 6,50 \cdot 7$ & $49 \cdot 9$ & $49 \cdot 6,50 \cdot 2$ & 0.08 & 0.22 \\
\hline Protein $(\mathrm{E} \%)$ & $17 \cdot 6$ & $17 \cdot 4,17 \cdot 8$ & $17 \cdot 3 \dagger$ & $17 \cdot 1,17 \cdot 5$ & $18 \cdot 0$ & $17 \cdot 9,18 \cdot 2$ & $<0.0001$ & $<0.0001$ \\
\hline Alcohol (E\%) & 1.43 & $1.25,1.61$ & $1.62^{*}$ & $1.42,1.82$ & 1.61 & $1.49,1.73$ & 0.23 & 0.04 \\
\hline Fibre $(\mathrm{g})$ 川 & 34.1 & $33.4,34.9$ & $32 \cdot 4^{\star}$ & $31 \cdot 6,33 \cdot 2$ & $32 \cdot 6$ & $32 \cdot 1,33 \cdot 1$ & 0.0007 & 0.02 \\
\hline Cereals $(\mathrm{g})$ & 180 & 176,184 & $169^{*}$ & 164,173 & 170 & 167,172 & $<0.0001$ & $<0.0001$ \\
\hline Rye (g) & 64.5 & $61 \cdot 6,67 \cdot 3$ & $59 \cdot 8^{*}$ & $56 \cdot 6,62 \cdot 9$ & $62 \cdot 0$ & $60 \cdot 1,63 \cdot 9$ & 0.08 & 0.05 \\
\hline Wheat (g) & 68.9 & $66.5,71 \cdot 3$ & 67.5 & $64 \cdot 8,70 \cdot 1$ & $65 \cdot 8$ & $64 \cdot 2,67 \cdot 4$ & 0.09 & 0.01 \\
\hline Potatoes $(\mathrm{g})^{\star *}$ & 113 & 108,119 & $116 \dagger$ & 110,122 & 125 & 121,129 & 0.0016 & 0.04 \\
\hline Vegetables (g) & 337 & 322,353 & $324 t$ & 307,341 & 357 & 347,368 & 0.0022 & 0.0001 \\
\hline Root vegetables (g) & 58.5 & $54 \cdot 7,62 \cdot 3$ & $52 \cdot 1^{*} \dagger$ & $47 \cdot 9,56 \cdot 3$ & 61.5 & $59 \cdot 0,64 \cdot 1$ & 0.0008 & 0.0002 \\
\hline Fruits $(g)+\dagger$ & 338 & 320,355 & 318 & 299,338 & 311 & 299,323 & 0.05 & 0.73 \\
\hline Juices $(\mathrm{g})$ & 108.9 & $97 \cdot 3,120 \cdot 5$ & $115 \cdot 8$ & $102 \cdot 8,128 \cdot 7$ & $102 \cdot 1$ & $94 \cdot 3,109 \cdot 9$ & 0.19 & 0.32 \\
\hline Fat $(\mathrm{g})$ & $40 \cdot 3$ & $39.1,41 \cdot 6$ & $41 \cdot 6$ & $40 \cdot 2,42 \cdot 9$ & $40 \cdot 9$ & $40 \cdot 1,41 \cdot 7$ & 0.39 & 0.57 \\
\hline Butter (g) & 6.44 & $5.97,6.92$ & 6.56 & $6.03,7.08$ & 6.34 & $6.03,6.66$ & 0.78 & 0.63 \\
\hline Margarine (g) & $12 \cdot 3$ & $11 \cdot 6,13 \cdot 1$ & 11.8 & $10 \cdot 9,12 \cdot 6$ & $12 \cdot 0$ & $11.5,12.5$ & 0.64 & 0.26 \\
\hline Oil (g) & 9.05 & $8.56,9.55$ & $9.66 \dagger$ & $9 \cdot 11,10 \cdot 21$ & 8.99 & $8.65,9.32$ & 0.11 & 0.17 \\
\hline Meat products (g) & 145 & 139,151 & $147 \dagger$ & 140,153 & 164 & 160,168 & $<0.0001$ & $<0.0001$ \\
\hline Pork (g) & $33 \cdot 2$ & $31.4,35 \cdot 0$ & $34 \cdot 1$ & $32 \cdot 1,36 \cdot 1$ & $36 \cdot 3$ & $35 \cdot 1,37.5$ & 0.01 & 0.11 \\
\hline Beef $(\mathrm{g})$ & 28.9 & $26 \cdot 8,31 \cdot 0$ & $30.5 \dagger$ & $28 \cdot 2,32 \cdot 8$ & 33.3 & $31 \cdot 9,34 \cdot 8$ & 0.0014 & 0.0047 \\
\hline Poultry (g) & 38.8 & $35 \cdot 9,41 \cdot 6$ & $34.9 \dagger$ & $31 \cdot 7,38 \cdot 1$ & $40 \cdot 9$ & $39 \cdot 0,42 \cdot 8$ & 0.0066 & 0.0015 \\
\hline Sausage, processed meat (g) & 34.8 & $32 \cdot 0,37 \cdot 6$ & $38.4 \dagger$ & $35 \cdot 3,41.5$ & 43.5 & $41 \cdot 6,45 \cdot 4$ & $<0.0001$ & 0.0016 \\
\hline Fish $(\mathrm{g})$ & 51.4 & $48 \cdot 2,54 \cdot 7$ & $45 \cdot 3^{\star}$ & $41.7,48.9$ & $47 \cdot 2$ & $45 \cdot 1,49 \cdot 4$ & 0.03 & 0.18 \\
\hline Eggs (g) & 23.4 & $22 \cdot 1,24 \cdot 7$ & 22.9 & $21 \cdot 5,24 \cdot 4$ & $23 . \overline{6}$ & $22 \cdot 8,24 \cdot 5$ & 0.71 & 0.70 \\
\hline Milk products (g) & 577 & 553,601 & $567 \dagger$ & 541,594 & 605 & 589,621 & 0.03 & 0.08 \\
\hline Milk (g) & 287 & 268,307 & $284 \dagger$ & 263,306 & 311 & 298,324 & 0.04 & 0.12 \\
\hline Fermented milk products $(\mathrm{g})$ & 215 & 199,231 & 215 & 197,233 & 223 & 212,234 & 0.61 & 0.62 \\
\hline Cheese $(\mathrm{g})$ & 46.5 & $43 \cdot 9,49 \cdot 1$ & $41 \cdot 3^{*}$ & $38 \cdot 4,44 \cdot 2$ & $42 \cdot 8$ & $41 \cdot 1,44 \cdot 6$ & 0.02 & 0.02 \\
\hline Coffee $(\mathrm{g})$ & 357 & 338,377 & 377 & 356,398 & 388 & 376,401 & 0.03 & 0.07 \\
\hline Tea $(\mathrm{g})$ & 226 & 205,248 & $167^{\star}$ & 143,191 & 158 & 144,173 & $<0.0001$ & $<0.0001$ \\
\hline Soft drinks (g) & 38.6 & $26 \cdot 9,50 \cdot 3$ & $47.4 \dagger$ & $34 \cdot 4,60 \cdot 4$ & $77 \cdot 0$ & $69 \cdot 2,84 \cdot 8$ & $<0.0001$ & $<0.0001$ \\
\hline Total sugar (g) & 38.8 & $35 \cdot 9,41.6$ & $51 \cdot 1^{*} \dagger$ & $47 \cdot 9,54 \cdot 3$ & $43 \cdot 0$ & $41 \cdot 1,44 \cdot 9$ & $<0.0001$ & $<0.0001$ \\
\hline Sugar, syrups (g) & $15 \cdot 9$ & $15 \cdot 2,16 \cdot 7$ & $15 \cdot 8$ & $15 \cdot 0,16 \cdot 7$ & $15 \cdot 4$ & $14 \cdot 9,16 \cdot 0$ & 0.54 & 0.24 \\
\hline Confectionery (g) & $17 \cdot 7$ & $15 \cdot 0,20 \cdot 5$ & $28.4^{*} \dagger$ & $25 \cdot 4,31.5$ & $20 \cdot 3$ & $18 \cdot 5,22 \cdot 1$ & $<0.0001$ & $<0.0001$ \\
\hline
\end{tabular}

$\mathrm{E} \%$, percentage of energy.

${ }^{*}$ Mean values were significantly different from those of lean women $(P<0.05 ; t$ test).

† Mean values were significantly different from those of overweight women $(P<0.05 ; t$ test).

$\ddagger$ Intakes of energy-yielding nutrients were adjusted for age; those of fibre and foods were adjusted for age and energy intake.

$\S$ Differences across the weight categories were assessed using the $F$ test.

$\|$ Adjusted for age, education, leisure-time physical activity, smoking, alcohol consumption and energy intake (excluded energy for energy-yielding nutrients).

I Energy adjusted using the residual method.

** 'Potatoes' also includes hot chips and fried potatoes.

††'Fruits' does not include juice.

whereas the proportion of low physically active participants in NWO women fell between that in lean and overweight women. Physical activity should influence long-term weight gain, but findings to support this expectation have been surprisingly inconsistent ${ }^{(21-24)}$. In the present study, NWO men included more current smokers compared with the other weight categories. The prevalence of being ex-smokers was the highest in NWO women, whereas their prevalence of being current smokers was between that of lean and overweight women. The result concerning ex-smokers is consistent with prior findings that quitting smoking is associated with weight gain ${ }^{(25)}$. Smoking, in general, may adversely affect body mass distribution, promoting visceral rather than femoral or subcutaneous fat deposition ${ }^{(26)}$. The proportion of alcohol consumers in NWO men was in between that in lean and overweight men, whereas NWO women included more alcohol consumers compared with the other weight categories. Previous findings have indicated that the association between alcohol intake and weight change is complex ${ }^{(27)}$.

With regard to the intakes of energy-yielding nutrients, there were no differences between lean and NWO men or between NWO and overweight men. The protein intake of NWO women was similar to that of lean women, but lower than that of overweight women. Instead, the intakes of alcohol and fibre were similar between NWO and overweight women, but their intakes of alcohol were higher and intakes of fibre lower than those of lean women. It seems that lower protein intake may be a protective factor and high alcohol and low fibre intakes may be risk factors for the NWO syndrome. In all the weight categories the proportion 
of energy derived from carbohydrates was too low and that derived from protein was too high compared with the Nordic dietary recommendations ${ }^{(28)}$. While the present study is the first to focus on dietary factors and the NWO syndrome, the results cannot be compared with those of other studies. A recent systematic literature review has summarised that the percentage of macronutrients in the diet is not important for predicting changes in weight or waist circumference ${ }^{(29)}$.

The intake of beef was higher in NWO men than in the other weight categories, whereas the NWO women had the highest intake of sugar, especially of confectionery, and the lowest intake of root vegetables. The intakes of cereals, especially rye (women), fish (women), cheese (women) and tea (women) were similar between the NWO and overweight participants, but lower than the respective intakes of the lean participants. Furthermore, for example, the intakes of different types of meat, potatoes and soft drinks were similar to those of the lean participants, but lower than the respective intakes of overweight men. These findings may partly explain why the NWO participants were of normal weight but had a high body fat percentage. These results are consistent with previous findings that high intakes of sugar-sweetened beverages, sugar and confectionery might promote weight gain in the long term, whereas high intakes of whole grains, vegetables and fruits might promote energy balance ${ }^{(30-36)}$. A recent study carried out in three separate US cohorts has found positive associations between weight change and intakes of potato chips, potatoes, sugar-sweetened beverages and meat and negative associations between weight change and intakes of fruits, vegetables, whole grains, nuts and yogurt ${ }^{(27)}$. In a previous Finnish study, the increase in the intake of sugarsweetened soft drinks from childhood to adulthood has been reported to be positively associated with BMI in adulthood among women but not among men ${ }^{(37)}$. Differences between the results obtained for men and women may be explained by the general differences in their diet, e.g. added sugar is more common in the Finnish male diet, whereas confectioneries are more common in female diet ${ }^{(38)}$.

The strengths of the present study include the high number of randomly selected participants in Finland. Although the participation rate was at a reasonable level, we cannot exclude the possibility that non-participation might have affected the results. However, our findings could be an underestimate, because those who usually participate in health examination surveys tend to be more health conscious than non-participants ${ }^{(39)}$. Under-reporting of food intake is one of the major challenges when studying associations between diet and health ${ }^{(40)}$. However, in the present study, the results appeared to be similar when under-reporters were excluded. Because the study design was cross-sectional, we examined associations between lifestyle factors, diet and obesity, but not the causal effects.

From a public health perspective, identification of individuals with the NWO syndrome in primary health care might be useful for the early detection and prevention of obesity and obesity-related disorders. Specific unhealthy lifestyle characteristics and dietary factors are associated with the NWO syndrome.

\section{Acknowledgements}

The present study was supported by the Academy of Finland (136895 and 263836), and it had no role in the design and analysis of the study or in the writing of this article. The study did not receive any non-financial support.

The authors' contributions were as follows: S. M., N. E. K. and P. J. participated in the design and conduct of the study; S. M., M. L.-K., N. E. K. and S. E. S. participated in the design of the present study; K. H. and J. K. conducted the statistical analyses; S. M. wrote the manuscript and had the primary responsibility for the final content. All fellow authors critically reviewed the manuscript.

The authors declare no personal or financial conflicts of interest.

\section{References}

1. Kumanyika SK, Obarzanek E, Stettler N, et al. (2008) Population-based prevention of obesity: the need for comprehensive promotion of healthful eating, physical activity, and energy balance: a scientific statement from American Heart Association. Circulation 118, 428-464.

2. US Department of Health and Human Services (2001) Healthy People 2010: Understanding and Improving Health. Boston, MA: Jones and Bartlett Publishers.

3. Vartiainen E, Laatikainen T, Peltonen M, et al. (2010) Thirtyfive-year trends in cardiovascular risk factors in Finland. Int J Epidemiol 39, 504-518.

4. World Health Organization (2005) Risk Factor Projects. Overweight and Obesity. Geneva: World Health Organization. http://www.who.int/ (accessed 11 September 2007).

5. Karelis AD, St-Pierre DH, Conus F, et al. (2004) Metabolic and body composition factors in subgroups of obesity: what do we know? J Clin Endocrinol Metab 89, $2569-2575$.

6. Hayes L, Pearce MS, Firbank MJ, et al. (2010) Do obese but metabolically normal women differ in intra-abdominal fat and physical activity levels from those with the expected metabolic abnormalities? A cross-sectional study. BMC Public Health 10, 723.

7. De Lorenzo A, Del Gobbo V, Premrov MG, et al. (2007) Normal-weight obese syndrome: early inflammation. Am J Clin Nutr 85, 40-45.

8. Di Renzo L, Del Gobbo V, Bigioni M, et al. (2006) Body composition analyses in normal weight obese women. Eur Rev Med Pharmacol Sci 10, 191-196.

9. Marques-Vidal P, Pécoud A, Hayoz D, et al. (2008) Prevalence of normal weight obesity in Switzerland: effect of various definitions. Eur J Nutr 47, 251-257.

10. Marques-Vidal P, Pécoud A, Hayoz D, et al. (2010) Normal weight obesity: relationship with lipids, glycaemic status, liver enzymes and inflammation. Nutr Metab Cardiovasc Dis 20, 669-675.

11. Tolonen H, Koponen P, Aromaa A, et al. (2008) Recommendations for the Health Examination Surveys in Europe. Helsinki: National Public Health Institute (no. B21/2008).

12. Jebb SA, Cole TJ, Doman D, et al. (2000) Evaluation of the novel Tanita body-fat analyzer to measure body composition by comparison with a four-compartment model. Br J Nutr 83, $115-122$.

13. World Health Organization (2004) Obesity: Prevention and Managing the Global Epidemic. Report of a WHO Consultation. WHO Technical Report Series no. 894. Geneva: WHO. 
14. Männistö S, Virtanen M, Mikkonen T, et al. (1996) Reproducibility and validity of a food frequency questionnaire in a case-control study on breast cancer. J Clin Epidemiol 49, 401-409.

15. Kaartinen NE, Tapanainen H, Valsta LM, et al. (2012) Relative validity of a FFQ in measuring carbohydrate fractions, dietary glycaemic index and load: exploring the effects of subject characteristics. Br J Nutr 107, 1367-1375.

16. Reinivuo H, Hirvonen T, Ovaskainen ML, et al. (2010) Dietary survey methodology of FINDIET 2007 with a risk assessment perspective. Public Health Nutr 13, 915-919.

17. Willett W (2013) Nutritional Epidemiology, 3rd ed. New York: Oxford University Press.

18. FAO/WHO/UNU (1985) Report of a Joint Expert Consultation. Energy and Protein Requirements. WHO Technical Report Series no. 724. Geneva: WHO.

19. Goldberg GR, Black AE, Jebb SA, et al. (1991) Critical evaluation of energy intake data using fundamental principles of energy physiology: 1. Derivation of cut-off limits to identify under-recording. Eur J Clin Nutr 45, 569-581.

20. Black AE (2000) Critical evaluation of energy intake using the Goldberg cut-off for energy intake:basal metabolic rate A practical guide to its calculation, use and limitations. Int J Obes Relat Metab Disord 24, 1119-1130.

21. Haapanen N, Miilunpalo S, Pasanen M, et al. (1997) Association between leisure time physical activity and 10-year body mass change among working-aged men and women. Int J Obes Relat Metab Disord 21, 288-296.

22. Wagner A, Simon C, Ducimetière P, et al. (2001) Leisure-time physical activity and regular walking or cycling to work are associated with adiposity and $5 \mathrm{y}$ weight gain in middle-aged men: the PRIME Study. Int J Obes Relat Metab Disord 25, 940-948.

23. Gordon-Larsen P, Hou N, Sidney S, et al. (2009) Fifteen-year longitudinal trends in walking patterns and their impact on weight change. Am J Clin Nutr 89, 19-26.

24. Lee IM, Djoussé L, Sesso HD, et al. (2010) Physical activity and weight gain prevention. JAMA 303, 1173-1179.

25. Office on Smoking and Health National Center for Chronic Disease Prevention and Health Promotion (2011) Women and Smoking: A Report of the Surgeon General. Atlanta, GA: Centers for Disease Control and Prevention.

26. Willi C, Bodenmann P, Ghali WA, et al. (2007) Active smoking and the risk of type 2 diabetes: a systematic review and meta-analysis. JAMA 298, 2654-2664.
27. Mozaffarian D, Hao T, Rimm EB, et al. (2011) Changes in diet and lifestyle and long-term weight gain in women and men. $N$ Engl J Med 364, 2392-2404.

28. Nordic Council of Ministers (2004) Nordic Nutrition Recommendations, 4th ed. Copenhagen: Nordic Council of Ministers.

29. Fogelholm M, Anderssen S, Gunnarsdottir I, et al. (2012) Dietary macronutrients and food consumption as determinants of long-term weight change in adult populations: a systematic literature review. Food Nutr Res 56 (epublication ahead of print version 13 August 2012).

30. Ello-Martin JA, Ledikwe JH \& Rolls BJ (2005) The influence of food portion size and energy density on energy intake: implications for weight management. Am J Clin Nutr $\mathbf{8 2}$, Suppl. 1, 236S-241S.

31. van Dam RM \& Seidell JC (2007) Carbohydrate intake and obesity. Eur I Clin Nutr 61, Suppl. 1, S75-S99.

32. Rosenheck R (2008) Fast food intake and increased caloric intake: a systematic review of a trajectory towards weight gain and obesity risk. Obes Rev 9, 535-547.

33. Wolff E \& Dansinger ML (2008) Soft drinks and weight gain: how strong is the link? Medscape J Med 10, 189.

34. Micha R \& Mozaffarian D (2009) Trans fatty acids: effects on metabolic syndrome, heart disease and diabetes. Nat Rev Endocrinol 5, 335-344.

35. Liu S, Willett WC, Manson JE, et al. (2003) Relation between changes in intakes of dietary fiber and grain products and changes in weight and development of obesity among middle-aged women. Am J Clin Nutr 78, 920-927.

36. Buijsse B, Feskens EJ, Schulze MB, et al. (2009) Fruit and vegetable intakes and subsequent changes in body weight in European populations: results from the project on Diet, Obesity, and Genes (DiOGenes). Am J Clin Nutr 90, 202-209.

37. Nissinen K, Mikkilä V, Männistö S, et al. (2009) Sweets and sugar-sweetened soft drink intake in childhood in relation to adult BMI and overweight. The Cardiovascular Risk in Young Finns Study. Public Health Nutr 12, 2018-2026.

38. Paturi M, Tapanainen H, Reinivuo H, et al. (2008) The National FINDIET 2007 Survey (Summary in English). Helsinki: National Public Health Institute (no. B23/2008).

39. Colditz GA (2010) Overview of the epidemiology methods and applications: strengths and limitations of observational study designs. Crit Rev Food Sci Nutr 50, Suppl. 1, 10-12.

40. Hirvonen T, Männistö S, Roos E, et al. (1997) Increasing prevalence of underreporting does not necessarily distort dietary surveys. Eur J Clin Nutr 51, 297-301. 